\author{
C. Franssen MD, P. Hans MD, J.F. Brichant MD, \\ D. Noirot MD, M. Lamy MD
}

\title{
Comparison between alprazolam and hydroxyzine for oral premedication
}

The safety and efficacy of alprazolam and hydroxyzine administered orally as surgical premedicants were compared in a double-blind controlled study. Sixty-five patients were given either alprazolam $1 \mathrm{mg}$ or hydroxyzine $75 \mathrm{mg}$, one to two hours before surgery. Anxiety was assessed by both the patient and the anaesthetist, the patient using a visual analogue scale, the anaesthetist employing both analogue and ordinal ratings. Sedation was assessed by the anaesthetist only, using the same two methods. Amnesia was appraised with a simple memory test. Safety was assessed by recording adverse effects and measuring haemodynamic variables. Premedication with alprazolam produced a modest reduction in anxiety $(28 \%)(P<0.01)$ while hydroxyzine had no detectable effect. The comparison of the sedation level and of the memory test revealed no difference between the two premedicants. Minor side effects were only observed in the hydroxyzine group. Changes in blood pressure were more pronounced in the hydroxyzine group. This study shows that alprazolam and hydroxyzine are safe and efficient oral premedicants. However, alprazolam is preferable to hydroxyzine in terms of anxiolytic and adverse effects.

Au cours d'une étude à double insu, on compare la sécurité et l'efficacité de l'alprazolam et de l'hydroxyzine administrés par voie orale en prémédication. Soixante-six patients reçoivent alprazolam $1 \mathrm{mg}$ ou hydroxyzine $75 \mathrm{mg}$ de une à deux heures avant la chirurgie. Le patient et l'anesthésiste évaluent indi-

\section{Key words}

ATARACTICS: hydroxyzine;

HYPNOTICS: alprazolam, hydroxyzine, benzodiazepines; PREMEDICATION: alprazolam, hydroxyzine.

From the Department of Anaesthesiology, University Hospital of Liège, B35, Domaine Universitaire du Sart Tilman, B-4000 Liège, Belgium.

Address correspondence to: Dr C. Franssen, Department of Anaesthesiology, University Hospital of Liège (B35), B-4000

Sart Tilman Liège.

Supported by a grant from Upjohn Benelux, Puurs, Belgium.

Accepted for publication 19th September, 1992. viduellement le degré d'anxiété: le patient utilise une échelle visuelle analogique alors que l'anesthésiste utilise une classification ordinale en plus de l'échelle analogique. Grâce à ces deux méthodes, le sédation fait l'objet d'un évaluation par l'anesthésiste seul. L'amnésie est estimée par une test de mémoire simple. On évalue la sécurité des médicaments par l'enregistrement des effets défavorables et la mesure des variables hémodynamiques. La prémédication à l'alprazolam produit une baisse modeste de l'anxiété $(28 \%)(P<0,01)$ alors que l'hydroxyzine ne produit pas d'effets décelables. La comparaison entre les deux prémédications pour le degré de sédation et le test de mémoire ne révèle pas de différence. Des effets secondaires mineurs ne sont observés que dans le groupe hydroxyzine. Les changements tensionnels sont plus prononcés dans ce dernier groupe. Cette étude démontre que l'alprazolam et Ihydroxyzine sont en prémédication des médicaments sûrs et efficaces. Cependant l'alprazolam est supérieur à l'hydroxyzine sous l'aspect de l'anxiolyse et des effets secondaires.

The most common reasons for administering preanaesthetic medication are to relieve anxiety and to reduce awareness related to surgery. Premedicants are expected to allow the patient to enter the operating room with minimal apprehension, sedated but easily rousable, and cooperative without uncomfortable side effects. ${ }^{\prime}$

A major advantage of oral premedication is to avoid painful injection. Benzodiazepines are used extensively as oral premedicants. They are effective in producing anxiolysis and amnesia, and are associated with good patient acceptance. ${ }^{2,3}$ The efficacy and safety of alprazolam $\left(\right.$ xanax $\left.^{\circledR}\right)$ a new triazolobenzodiazepine, are well documented. 4,5 It was found to have the following properties: major anxiolysis, minor respiratory depression and a low incidence of drowsiness. After oral administration, it is rapidly absorbed and has a serum half-life of 12 to 15 $\mathrm{hr}$ following a single oral dose. Because of these characteristics, alprazolam can be considered as a potential presurgical medication. Hydroxyzine (Atarax ${ }^{\circledR}$ ) is an unique non-phenothiazine tranquilizer which has bronchodilator, anthihistaminc and analgesic effects. It has been found to be an effective surgical premedicant. ${ }^{6}$ 
The present study was designed to compare the efficacy and safety of alprazolam and hydroxyzine as oral premedicants.

\section{Methods}

After approval by the Hospital Ethical Committee and informed consent from each patient had been obtained, 65 ASA I-II patients, ages 16 to $65 \mathrm{yr}$ and scheduled for plastic or orthopaedic surgery were included in this randomized, double-blind study. Use of anxiolytic or sedative drugs, alcohol addiction, renal or hepatic insufficiency, myasthenia and intolerance or hypersensitivity to benzodiazepines or hydroxyzine were considered as exclusion criteria.

Thirty-four patients (52\%) were given alprazolam $1 \mathrm{mg}$ and 31 patients (48\%) received hydroxyzine $75 \mathrm{mg}$ orally one to two hours before induction of anaesthesia. Patients did not receive any other sedative or hypnotic drug either the evening before or during the day of surgery. Anaesthesia was induced with propofol $\left(2 \mathrm{mg} \cdot \mathrm{kg}^{-1}\right)$ and sufentanil $\left(0.1-0.2 \mu \mathrm{g} \cdot \mathrm{kg}^{-1}\right)$ and muscle relaxation was produced with atracurium $\left(0.5 \mathrm{mg} \cdot \mathrm{kg}^{-1}\right)$. Maintenance of anaesthesia was with isoflurane and $50 \% \mathrm{~N}_{2} \mathrm{O}$ in $\mathrm{O}_{2}$. All patients recovered in the operating room immediately after surgery. Postoperative analgesia consisted of proparacetamol $i v$ according to the patient request.

The efficacy of the premedicants was evaluated by assessments of anxiety and sedation and by the results of a memory test. ${ }^{7-10}$ Anxiety level and degree of sedation were recorded before premedication $\left(\mathrm{T}_{1}\right)$ before induction of anaesthesia $\left(\mathrm{T}_{2}\right)$ and on the evening after surgery $\left(\mathrm{T}_{3}\right)$. The level of anxiety was assessed by the patient and by the anaesthetist, using a $10 \mathrm{~cm}$ visual analogue scale (VAS) $(0 \mathrm{~cm}=$ relaxed, $\ldots, 10 \mathrm{~cm}=$ very anxious). In addition, anxiety was evaluated by the anaesthetist using a seven point clinical global impression (CGI) scale of anxiety $(0=$ relaxation, $1=$ apprehension, $2=$ mild anxiety, $3=$ moderate anxiety, $4=$ manifest anxiety, $5=$ severe anxiety, $6=$ very severe anxiety).

The degree of sedation was assessed by the anaesthetist using a $10 \mathrm{~cm}$ VAS $(0 \mathrm{~cm}=$ excited, $\ldots, 10 \mathrm{~cm}=$ asleep) and a five-point CGI of sedation ( $0=$ awake, $1=$ mild sedation, $2=$ moderate sedation, $3=$ pronounced sedation, $4=$ very pronounced sedation). The anaesthetist was unaware of the premedicant administered.

A memory test performed the evening after surgery consisted of four questions to which the patients had to answer yes or no $=$ "Do you recognize the bank note shown at the premedication time?," "Do you remember leaving your room?," "Do you remember the operating room?," "Do you remember going to sleep in the operating room?"
Safety was evaluated based on the global assessment of the tolerance by the patient, the adverse effects reported and the evolution of vital signs (blood pressure (BP), heart rate (HR), respiratory rate (RR)) during the period of study. To express global acceptance, each patient was requested to qualify the premedication as satisfactory, unsatisfactory or indifferent; no specific question was asked to the patient. All adverse signs and symptoms reported by the patient to the anaesthetist on the evening after surgery or observed by the anaesthetist in the operating room and in the recovery room were noted. Vital signs were recorded by the anaesthetist at $T_{1}, T_{2}$ and $T_{3}$.

\section{Statistical analysis}

All statistical tests carried out were two sided at the $5 \%$ level of significance. Discrete variables were compared on the basis of the chi-square test (two by two tables) or the Fisher exact test (small frequencies). Continuous variables were compared using the $t$ test for independent samples and the Mann-Whitney test. The VAS assessment in the two groups were compared using repeated measures analysis of variance (ANOVA). The CGI assessment was evaluated on the basis of the different scores observed during consecutive visits. Differences between the two groups were analyzed by the Mann-Whitney test. Finally, results of the memory test, patient acceptance and incidence of adverse events were compared using the Fisher exact test.

\section{Results}

The two groups were similar in terms of demographic data, ASA status and timing of drug administration with respect to surgery (Table I). Before premedication, VAS and CGI data revealed no difference in the level of anxiety and sedation between the two groups.

\section{Assessment of anxiety}

The evolution of the VAS assessments of anxiety by the patient during the trial was different between the two groups $(P<0.05)$ (Figure 1). Anxiety did not change from $T_{1}$ to $T_{2}$ in the hydroxyzine group while it decreased in the alprazolam group $(P<0.01)$ during the same period. There was a decrease in the anxiety VAS assessments by the anaesthetist (Figure 2) level between $T_{1}$ and $\mathrm{T}_{2}(P<0.001)$ and also between $\mathrm{T}_{2}$ and $\mathrm{T}_{3}(P$ $<0.01)$ in the alprazolam group. In the hydroxyzine group, no difference was observed between $T_{1}$ and $\mathrm{T}_{2}$. The anxiety decreased between $\mathrm{T}_{2}$ and $\mathrm{T}_{3}(P$ $<0.01$ ).

The evolution of the CGI assessments between $T_{1}$ and $\mathrm{T}_{2}$ was different between the two groups $(P<0.05$ ). Hydroxyzine-treated patients became more anxious at $T_{2}$. The anxiety partially disappeared at $T_{3}$ (Figure 3 ). 
TABLE I Demographic data of patients included in the study

\begin{tabular}{|c|c|c|c|}
\hline Variable & Alprazolam & Hydroxyzine & All patients \\
\hline \multicolumn{4}{|l|}{ Age $(y r)$} \\
\hline Mean & 39.7 & 37.6 & 38.7 \\
\hline SD & 11.1 & 10.8 & 40.9 \\
\hline Range & $17-60$ & $17-64$ & $17-64$ \\
\hline$n$ & 34 & 31 & 65 \\
\hline \multicolumn{4}{|c|}{ Weight $(k g)$} \\
\hline Mean & 71.6 & 70.8 & 71.2 \\
\hline SD & 15.4 & 13.1 & 14.2 \\
\hline Range & $48-120$ & $43-100$ & $43-120$ \\
\hline$n$ & 31 & 31 & 62 \\
\hline \multicolumn{4}{|c|}{ Delay (time ( $\min$ ) between premedication and induction) } \\
\hline Mean & 86.9 & 79.3 & 83.3 \\
\hline SD & 22.8 & 20.4 & 21.9 \\
\hline Range & $45-140$ & $60-120$ & $45-140$ \\
\hline$n$ & 32 & 28 & 60 \\
\hline \multicolumn{4}{|l|}{$\operatorname{Sex}$} \\
\hline Male & $23(68 \%)$ & $18(58 \%)$ & $41(63 \%)$ \\
\hline Female & $11(32 \%)$ & $13(42 \%)$ & $24(37 \%)$ \\
\hline \multicolumn{4}{|l|}{$A S A$} \\
\hline I & $29(88 \%)$ & $23(77 \%)$ & $52(83 \%)$ \\
\hline I to II & $1(3 \%)$ & $0(0 \%)$ & $1(2 \%)$ \\
\hline II & $3(9 \%)$ & $7(23 \%)$ & $10(15 \%)$ \\
\hline Missing & 1 & 1 & 2 \\
\hline
\end{tabular}

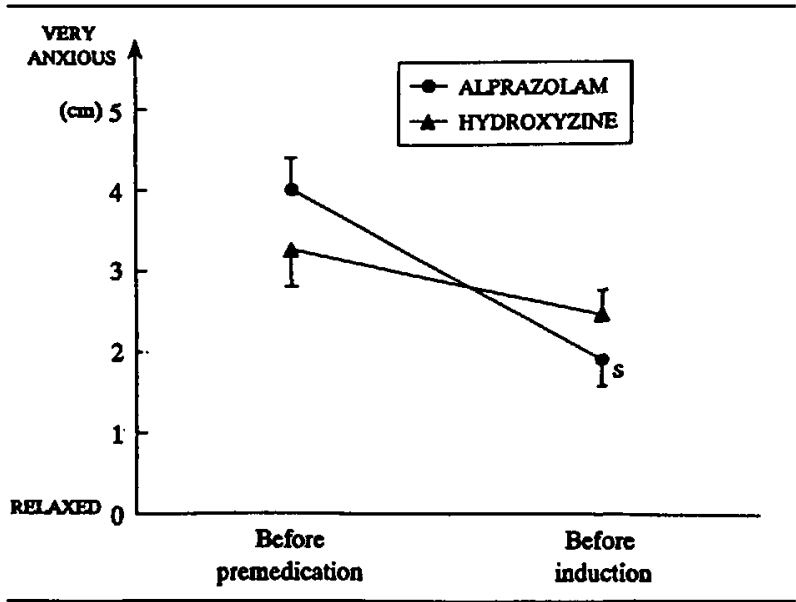

FIGURE 1 Evolution of the VAS assessments of anxiety reconded by the patients before premedication and before induction of general anaesthesia. Anxiety decreased only in the alprazolam group $(\mathrm{S})(P<$ 0.01).

\section{Assessment of sedation}

Sedation (assessed by VAS) decreased considerably ( $P$ $<0.001$ ) in both groups during the course of the study but no difference between the two groups was observed (Figure 4).

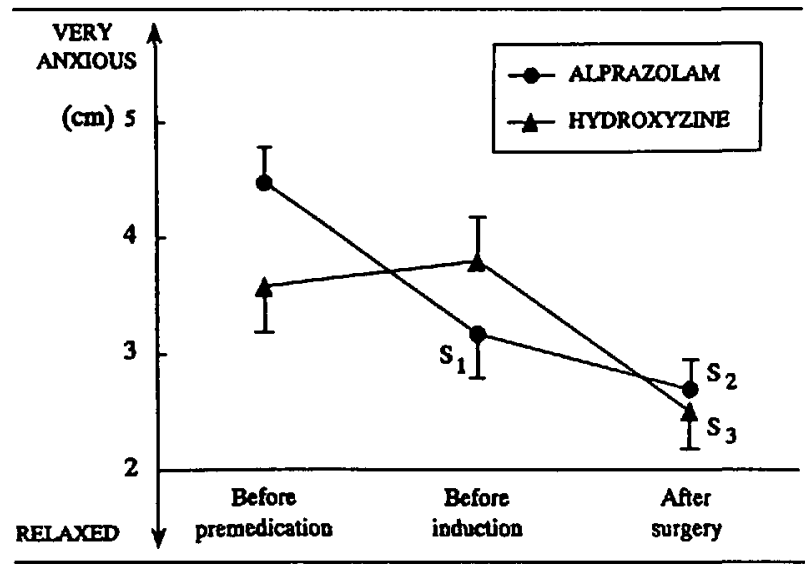

FIGURE 2 Evolution of the VAS assessments of anxiety recorded by the anaesthetist before premedication, before induction of anaesthesia and at the evening after surgery. Alprazolam group: $S_{1}(P<0.001$ between $T_{1}$ and $\left.T_{2}\right), S_{2}\left(P<0.01\right.$ between $T_{2}$ and $\left.T_{3}\right)$. Hydroxyzine group: $S_{3}\left(P<0.01\right.$ between $T_{2}$ and $\left.T_{3}\right)$.

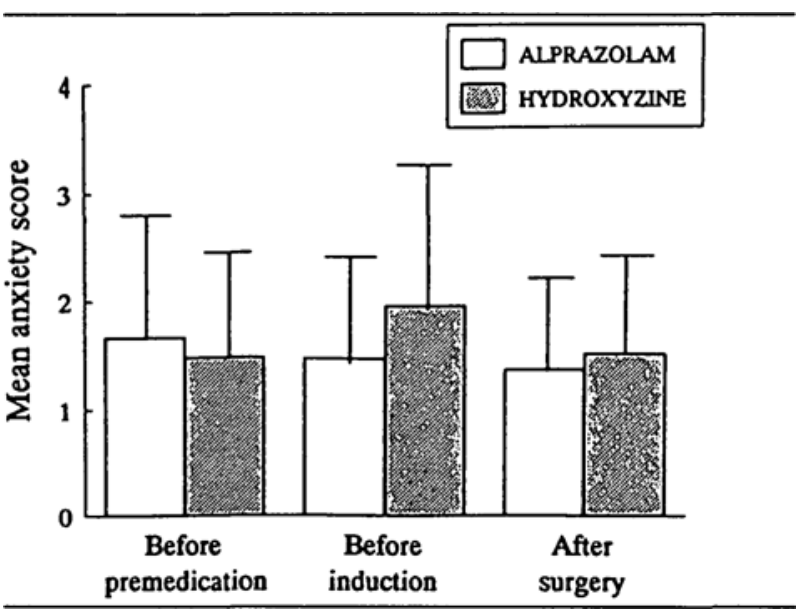

FIGURE 3 Mean anxiety scores (CGI scores) for the two treatment groups recorded by the anaesthetists before premedication, before induction and at the evening after surgery (mean $\pm S D$ ).

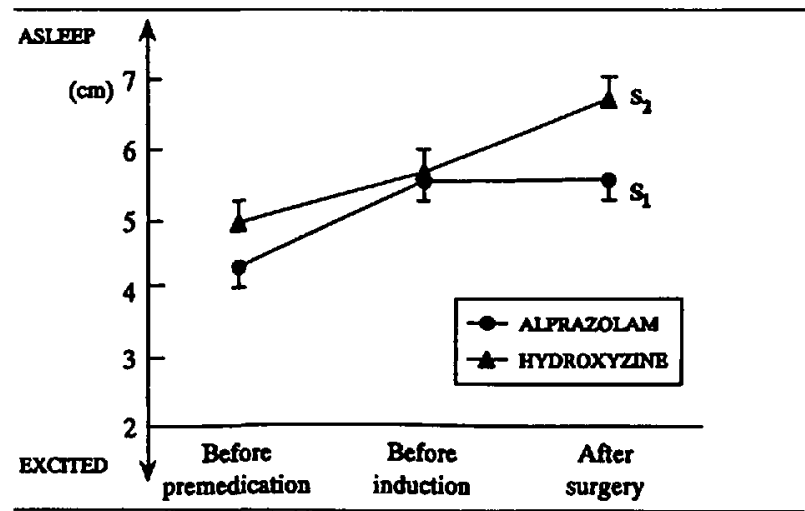

FIGURE 4 Evolution of the VAS assessments of sedation before premedication, before induction of anaesthesia and at the evening after surgery. Alprazolam group: $S_{1}\left(P<0.001\right.$ between $T_{1}$ and $\left.T_{3}\right)$. Hydroxyzine group: $S_{2}\left(P<0.001\right.$ between $T_{1}$ and $\left.T_{3}\right)$. 


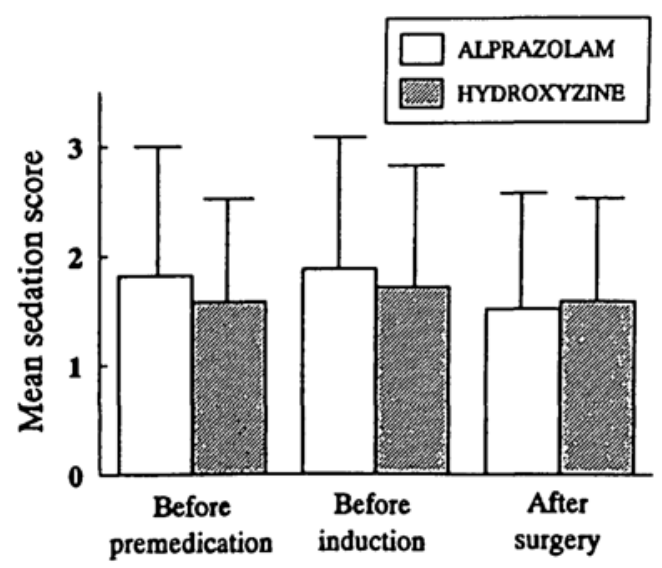

FIGURE 5 Mean sedation scores (CGI scores) for the two treatment groups recorded by the anaesthetists before premedication, before induction and on the evening after surgery (mean $\pm \mathrm{SD}$ ).

When assessing the level of sedation by means of CGI scores, no difference was observed at any time between the two groups (Figure 5).

\section{Memory test}

Statistical analysis of the memory test data did not reveal any difference between the two groups. No amnesic effect was noted with either alprazolam or hydroxyzine.

\section{Patient acceptance}

Alprazolam and hydroxyzine were rated as satisfactory premedicants respectively by 25 out of $34(73,5 \%)$ patients and by 20 out of $31(64,5 \%)$ patients but the difference in patient acceptance did not reach statistical significance.

\section{Adverse effects}

According to the patients, there was no difference in adverse events between the two groups. However, the incidence of side effects reported by the anaesthetist was higher $(P<0.01)$ in the hydroxyzine group (28\%) than in the alprazolam group (0\%). These effects consisted of anxiety, stress, pain, drowsiness, gastro-intestinal problems and agitation at awakening.
Vital signs

No differences were observed between the groups before premedication. Both systolic and diastolic BP increased in the two groups between $T_{1}$ and $T_{2}$ and subsequently decreased between $T_{2}$ and $T_{3}$. The changes in systolic $B P$ were larger in the hydroxyzine than in the alprazolam group $(P<0.01)$. Respiratory rate and mean heart rate remained unchanged in both groups (Table II).

\section{Discussion}

This study was designed to assess and compare the efficacy and the safety of two oral premedicants: alprazolam and hydroxyzine. In agreement with the Ethical Committee, no placebo group was included in the trial to avoid unwanted effects related to stress and anxiety. ${ }^{6}$

Oral administration of premedicants is now largely recommended. It is appreciated by patients, nurses and anaesthetists because it is easy to use and comfortable, and avoids painful injection. ${ }^{2,3}$ Given with a limited amount of water, it does not increase the risk of gastric aspiration during anaesthesia. ${ }^{11,12}$

The comparison of the two groups revealed no difference in anxiety and sedation before premedication. The basal level of anxiety was low in the majority of patients at the beginning of the study. The measurement of anxiety and sedation in patients is difficult but the linear analogue scale and the CGI scale provide sensitive and accurate subjective assessments of these phenomena. ${ }^{7}$ The anxiety level of the patients given alprazolam decreased during the trial. This decrease was greater between $T_{1}$ and $T_{2}$ than in the post-surgery period. Simultaneously, VAS assessment of anxiety did not reveal any change in the hydroxyzine group. On the basis of CGI scale, anxiety of hydroxyzine treated patients was greater at $T_{2}$ than at $T_{1}$. Therefore, we conclude that alprazolam premedication provided a better anxiolytic effect than hydroxyzine.

Sedation data are not consistent regarding the two methods of evaluation. The VAS assessment of sedation demonstrated decreased sedation in both groups during the trial. However, CGI assessment of sedation failed to demonstrate any change. This discrepancy could be ex-

TABLE II Evolution of vital signs in each group during the trial

\begin{tabular}{|c|c|c|c|c|c|c|}
\hline & \multicolumn{3}{|l|}{ Alprazolam } & \multicolumn{3}{|l|}{ Hydroxyzine } \\
\hline & $T_{l}$ & $T_{2}$ & $T_{3}$ & $T_{l}$ & $T_{2}$ & $T_{3}$ \\
\hline Systolic BP (mmHg) & $124.4 \pm 11.4$ & $126 \pm 17.8^{*}$ & $123.7 \pm 16.8^{*}$ & $120.7 \pm 17.8$ & $129.2 \pm 18.5^{*}$ & $113.7 \pm 12.5^{*}$ \\
\hline Diastolic BP $(\mathrm{mmHg})$ & $71.6 \pm 9.8$ & $75.7 \pm 9.2^{*}$ & $71.8 \pm 11.5^{*}$ & $72.9 \pm 9$ & $77.9 \pm 12.6^{*}$ & $68.9 \pm 9 *$ \\
\hline HR (Beats $\cdot \mathrm{min}^{-1}$ ) & $72 \pm 11$ & $74 \pm 12$ & $75 \pm 12$ & $71 \pm 8$ & $74 \pm 12$ & $72 \pm 10$ \\
\hline $\mathrm{RR}(\mathrm{ppm})$ & $16 \pm 3$ & $15 \pm 2$ & $15 \pm 3$ & $17 \pm 3$ & $17 \pm 3$ & $17 \pm 2$ \\
\hline
\end{tabular}

${ }^{*} P<0.001$. The changes in systolic BP were more pronounced in the hydroxyzine group $(P<0.01)$. 
plained by the very low degree of sedation of the patients in each group. The majority of sedated patients were in a light sleeping state from which they were easily aroused.

The study failed to demonstrate any amnesic effect of the two drugs. The recall of presurgical events was preserved in the majority of patients. This is surprising for alprazolam premedication because benzodiazepines produce lack of recall of presurgical events more consistently than other drugs such as hydroxyzine. ${ }^{6}$ However, previous studies have identified alprazolam as a potent antianxiety agent with a lower incidence of benzodiazepine pharmacology related side effects such as drowsiness and amnesia. 4,5

Safety evaluation of the premedicants was based upon the global assessment of tolerance by the patient, the frequency of reported adverse events and the evolution of vital signs during the trial. Both alprazolam and hydroxyzine were rated by the patients as satisfactory premedicants. The anaesthetist reported minor side effects only in the hydroxyzine group (28\% of patients). In the absence of a control group, it is impossible to state if these effects were specifically related to hydroxyzine or rather resulted from its lower anxiolytic effect. Indeed, patients given alprazolam were more relaxed when entering the operating room and experienced no side effects.

Finally, regarding vital signs, statistical analysis revealed a difference between the two groups only in the systolic BP which was higher at $T_{2}$ in the hydroxyzine group. Once again, this finding was probably related to the higher level of anxiety of patients at that time.

In conclusion, alprazolam and hydroxyzine are both efficient and safe pre-anaesthetic medications. However, a more pronounced, although modest, anxiolysis and the absence of side effects favours the use of alprazolam over hydroxyzine.

\section{References}

1 White $P F$. Pharmacologic and clinical aspects of preoperative medication. Anesth Analg 1986; 65: 963-74.

2 Kanto J. Benzodiazepines as oral premedicants. $\mathrm{Br} \mathrm{J}$ Anaesth 1981; 53: 1179-88.

3 Hofstad B, Haavik PE, Wickstrom E, Steen PA. Benzodiazepines as oral premedication. A comparison between oxazepam, flunitrazepam and placebo. Acta Anaesthesiol Scand 1987; 31: 295-9.

4 Dawson GW, Jue SG, Brogden RN. Alprazolam: a review of its pharmacodynamic properties and efficacy in the treatment of anxiety and depression. Drugs 1984; 27 : 132-47.

5 Fawcett JA, Howard MK. Alprazolam: pharmacokinetics, clinical efficacy, and mechanism of action. Pharmacotherapy 1982; 2: 243-54.
6 Wallace G, Mindlin $L J$. A controlled double-blind comparison of intramuscular lorazepam and hydroxyzine as surgical premedicants. Anesth Analg 1984; 63: 571-6.

7 Maxwell $C$. Sensitivity and accuracy of visual analogue scale: a psycho-physical classroom experiment. $\mathrm{Br} \mathrm{J}$ Clin Pharmacol 1978; 6: 15-24.

8 Bond $A$, Laden $M$. The use of analogue scales in rating subjected feelings. Br J Med Psychol 1974; 47: 211-8.

9 Van Wijhe M, De Voogt-Frenkel E, Stijnen T. Midazolam versus fentanyl, droperidol and placebo as intramuscular premedicant. Acta Anaesthesiol Scand 1985; 29: 409-14.

10 Raybould D, Bradshaw EG. Premedication for day case surgery. Anaesthesia 1987; 42: 591-5.

11 Splinter WM, Stewart JA, Muir JG. The effect of preoperative apple juice on gastric contents, thirst and hunger in children. Can J Anaesth 1989; 36, 1: 55-8.

12 McGrady EM, McDonald AG. Effect of the preoperative administration of water on gastric volume and $\mathrm{pH}$. $\mathrm{Br} \mathrm{J}$ Anaesth 1988; 60: 803-5. 